\title{
Sincronização do estro em bovinos de acordo com a fase do ciclo estral
}

\section{Bovine estrus sinchronization according to estrous cycle phase}

\author{
C.A.C. Fernandes' ${ }^{1}$, A.M. Ferreira ${ }^{2}$, W.F. Sá2 ${ }^{2}$ A.C.S. Figueiredo ${ }^{1}$
}

\section{Resumo}

Utilizaram-se 133 novilhas mestiças holandês-zebu, como receptoras, num programa de transferência de embrião. Esses animais tiveram o estro sincronizado com 0,375 mg de cloprostenol sódico, intravulvar, em duas fases do ciclo estral. No grupo 1 (T1) foram feitas 79 aplicações do tratamento entre $05^{\circ}$ e $8^{\circ}$ dia do ciclo estral, e no grupo 2 (T2) 128 aplicações entre o $9^{\circ}$ e $17^{\circ}$ dia. Os animais foram mantidos em piquetes com rufiōes e tiveram 0 estro observado três vezes ao dia ( $30 \mathrm{~min}$. cada). A eficiência de sincronização foi de $63,4 \%$ para T1 contra $80,2 \%$ para T2 $(p<0,05)$. O tempo decorrido entre a aplicação e o início do estro foi de $57,44+10,13 \mathrm{~h}$ para T1 e $71,87+$ $22,02 \mathrm{~h}$ para T2 $(p<0,01)$. Concluiu-se que a fase do ciclo estral, na qual se aplicou o tratamento, influenciou no intervalo até o estro (maior em T2) e na eficiência da sincronização (maior em T2).

Palavras chave: sincronização de estro; folículo; bovino

\section{Introdução}

A sincronização do estro, através da aplicação de agentes luteolíticos, como a prostaglandina (PGF2 $\alpha$ ) ou seus análogos, tem sido amplamente utilizada, tanto em casos de monta natural ou inseminação artificial quanto na técnica de transferência de embriōes, para a qual é imprescindivel. Trata-se de um método prático, de baixo custo, que induz um estro de fertilidade comparado ao natural. Existe um ponto de estrangulamento, principalmente na sincronização de estros entre doadoras e receptoras, que deve se situar dentro de uma faixa estreita de tempo, que não tem sido observado pela grande variação no tempo de resposta dos animais, fazendo com que parte das receptoras sincronizadas não se situem dentro do período em que possam receber o embrião (Fernandes, 1994).

$O$ dia do ciclo estral em que o animal se encontra ao receber a PGF2 $\alpha$ inclui-se entre os vários fatores capazes de influenciar o intervalo entre a aplicação do luteolítico e o estro. Segundo Spicer e Echternkamp (1986) existem períodos determinados do ciclo onde vários pequenos folículos iniciam o crescimento simultaneamente; tal fe- nômeno é chamado de ondas de crescimento folicular. A existência de duas ou três ondas de crescimento folicular durante 0 ciclo estral em bovinos foi postulada por Rajakoski (1960) e confirmada por Ireland e Roche (1983), Pierson e Ginter (1987a), Fortune et al. (1988), Fortune (1993) e Adams (1994).

As ondas de crescimento folicular ocorrem mesmo em períodos em que os níveis de gonadotrofinas estejam basais. Elas surgem nos dias 0 a 1 e 9 a 11 nos casos de duas ondas por ciclo, e nos dias 0 a 1,8 a 9 e 15 a 16 em animais com três ondas por ciclo, existindo porém, uma maior incidência de ciclos com duas ondas foliculares (Sirois e Fortune, 1988; Fortune, 1993). Na primeira onda folicular, o folículo dominante ou ovulatório atinge seu desenvolvimento máximo, porém não terá condições de ovular, entrando em atresia em função de não ter suporte hormonal para o processo de ovulação, devido à alta concentração de progesterona produzida pelo corpo lúteo nesse período do ciclo estral (Henricks et al., 1970; Hafez, 1987). Assim, uma nova onda folicular se inicia e o folículo dominante da onda anterior permanece no ovário por quatro a cinco dias quando então, gradativamente, desaparece. Na segunda onda de crescimento folicular, que se inicia no meio do ciclo, o folículo dominante, que será selecionado em torno do dia 17 a 18, terá condições de ovular, visto que, a partir desses dias, os níveis de progesterona estarão reduzidos devido ao processo de luteólise.

Sirọis e Fortune (1988) indicam correlação negativa entre o tamanho do folículo dominante, no início da regressão do corpo lúteo, e o tempo decorrido até o estro. O folículo destinado a ovular seria o maior folículo nos ovários, apenas um dia antes ou no dia do estro (Matton et al., 1981; Pierson e Ginter, 1987 a,b). A seleção ocorre três a quatro dias antes da ovulação e, além de um estímulo ao desenvolvimento no folículo ovulatório, parece existir também um bloqueio no desenvolvimento dos demais, pois a resposta desses às gonadotrofinas exógenas é menor após a seleção (Pierson e Ginter, 1987b).

Quando se aplica prostaglandina em fêmeas bovinas, visando a sincronização de estro, ocorre situação semelhante. Esse produto provoca a regressão do corpo

\footnotetext{
'Instituto de Ciencias Agrárias e Medicina Veterinária, Unifenas, Alfenas, MG, Brasil

2 EMBRAPA-CNPGL
} 
lúteo, com conseqüente redução nos níveis sangüíneos de progesterona, possibilitando a ovulação. Entretanto, 0 tempo decorrido até essa nova ovulação dependerá do estágio do desenvolvimento folicular, o que é variável nos diversos dias do ciclo. O objetivo do presente trabalho é o de verificar possíveis diferenças no tempo decorrido da aplicação de cloprostenol sódico, em diferentes fases do ciclo estral, até a manifestação de estro em novilhas.

\section{Material e Métodos}

O experimento foi conduzido nas dependências da Empresa Associl Agropecuária, no município de Platina, sudoeste do Estado de São Paulo. Foram avaliadas 207 aplicações intravulvares de $0,375 \mathrm{mg}$ de cloprostenol sódico, visando a sincronização de estro em 133 novilhas mestiças holandês $x$ zebu utilizadas como receptoras de embrião. Esses animais foram selecionados por possuírem peso vivo acima de $350 \mathrm{~kg}$; estarem ciclando em intervalos regulares; não possuírem anormalidades no trato genital detectável à palpação retal ou vaginoscopia; apresentarem condição corporal no mínimo razoável (escore 3, de 1 a 5 segundo Lowan, 1985, citado por Gonzalez (1991); e estarem entre o $5^{\circ}$ e $17^{\circ}$ dia do ciclo estral (estro dia 0).

As novilhas foram distribuídas em dois grupos de acordo com o período do ciclo estral em que se encontravam no ato da sincronização. No grupo 1 (T1) foram realizadas 79 aplicações em animais entre o $5^{\circ}$ e $8^{\circ}$ dia do ciclo, enquanto no grupo 2 (T2) foram feitas 128 aplicações em fêmeas que se encontravam entre o $9^{\circ}$ e $17^{\circ}$ dia do ciclo. Foram avaliados a eficiência do método de sincronização (animais em estro até $96 \mathrm{~h}$ após o tratamento) e o tempo decorrido da aplicação ao início dos sinais de estro.

Antes e após a sincronização, os animais foram mantidos em piquetes, na presença de rufiões, com três observações diárias de estro, durante $30 \mathrm{~min}$. cada, considerando-se o reflexo de imobilidade como indicativo do estro.

Nas análises estatísticas utilizaram-se o teste de 't' para comparar as médias do intervalo aplicação-estro e o teste de $\chi^{2}$ para comparação da eficiência entre os tratamentos. Para tais análises foi usado o programa de computador SAEG (Sistema de Análise Estatística e Genética; Euclides, 1982).

\section{Resultados e Discussão}

O grupo 1 apresentou menor período entre a aplicação de cloprostenol sódico e o surgimento do estro $(p<0,01)$, provavelmente, em função dos animais do grupo l encontrarem-se na ocasião do tratamento na fase do desenvolvimento folicular correspondente à metade final da primeira onda, quando o folículo dominante já poderia ter sido selecionado e estar em condições de ovular rapidamente (Tabela). Em T2, o produto foi aplicado no momento do início da segunda onda de crescimento folicular, quando o folículo ovulatório poderia ainda não ter sido selecionado ou estaria em início de desenvolvimento, havendo necessidade de um período maior até à ovulação considerando-se duas ou três ondas foliculares por ciclo estral.

A eficiência do tratamento foi melhor em T2, provavelmente devido a uma maior quantidade de receptores para a PGF2 $\alpha$ (ou análogos). Essa eficiência da sincronização (número de animais em estro até $96 \mathrm{~h}$ após o tratamento) depende da luteólise e queda dos níveis de progesterona, porém o intervalo até o início das manifestações de estro varia de acordo com o estágio de desenvolvimento folicular no momento que a concentração plasmática de progesterona diminui (Momont e Seguin, 1992). Embora o grupo II tenha apresentado melhores resultados na indução do estro, os animais na fase do ciclo estral relativa ao grupo I não podem ser desconsiderados dentro de um programa comercial de transferência de embriōes, pois o número de animais disponíveis como receptoras reduziria substancialmente.

Tabela - Fases do ciclo estral, eficiência da sincronização (número de animais em estro até $96 \mathrm{~h}$ após o tratamento) e intervalos médios com respectivos desvios padrão do tratamento com cloprostenol ao estro

\begin{tabular}{lcrcc}
\hline Grupo & $\begin{array}{c}\text { Período do } \\
\text { ciclo estral }\end{array}$ & N & Eficiência (\%) & \multicolumn{1}{l}{$\begin{array}{l}\text { Intervalo } \\
\text { aplicação } \\
\text {-estro }(h)^{\star \star}\end{array}$} \\
\hline II & $5^{\circ}-8^{\circ}$ & 79 & 63,4 & $57,44+10,13$ \\
\hline $9^{\circ}-17^{\circ}$ & 128 & 80,2 & $71,87+22,02$ \\
\hline Total & - & 207 & 68,02 & $68,02+13,15$ \\
\hline
\end{tabular}

${ }^{*}: p<0,05 ;{ }^{* *}: p<0,01$

Adams (1994) relata a existência de uma considerável variação do intervalo tratamento ao estro e ovulação que é atribuída ao status da onda folicular no momento do tratamento, ou seja, à população folicular e estágio de desenvolvimento dos folículos (MacMillan e Handerson, 1983). O período de resposta à prostaglandina em diferentes dias do ciclo estral é dependente do estágio no qual se encontra o folículo dominante (Kastelic et al., 1990). Os achados ou afirmações dos autores citados foram confirmadas em nosso experimento.

Quirl et al. (1986), através de acompanhamento ultrasonográfico de novilhas que receberam luteolítico nos dias 13 a 15 do ciclo, relatam que não foi o maior folículo presente nos ovários que ovulou: Esse sofreu regressão, e um outro foi selecionado de uma população de pequenos que iniciava o crescimento. O maior folículo observado inicialmente tratava-se do dominante da primeira onda que já se encontrava em atresia, sem condições de ovular, havendo então seleção e ovulação de um pertencente à segunda onda, em média $72 \mathrm{~h}$ após a aplicação, semeIhante aos resultados do presente trabalho, apresentada pelos animais de T2. 
Segundo Adams (1994), quando a luteólise é induzida na presença de um folículo dominante já selecionado e ainda em desenvolvimento, a ovulação e o estro ocorrem em um intervalo menor em comparação ao mesmo processo efetuado na presença de um folículo dominante já em atresia. Nesse caso será selecionado um folículo ovulatório (dominante) da próxima onda que necessitará de período maior para desenvolvimento da ovulação. 0 folículo dominante, durante seu desenvolvimento, bloqueia uma nova onda que somente tem inicio após sua atresia (Ko et al., 1991; Adams et al., 1993; Fortune, 1993). Essa situação provavelmente ocorreu nos tratamentos 1 e 2 onde os animais de T2 apresentaram um maior intervalo da aplicação ao estro quando comparado a T1.

\section{Conclusões}

O presente estudo mostra que a fase do ciclo estral em novilhas mestiças, em que é feita a aplicação do luteolítico, influencia o intervalo do tratamento ao surgimento do estro e a eficiência da sincronização. A eficiência de indução de estro é melhor quando o cloprostenol sódico é aplicado do $9^{\circ}$ ao $17^{\circ}$ dia do ciclo estral, porém o intervalo até o início do estro é maior.

\section{Abstract}

\section{Bovine estrus sinchronization according to estrous cycle phase}

We studied 133 crossbreed heifers, in embryo transfer program, for embryo recipients. The animals were synchronizated with $0.375 \mathrm{mg}$ of sodic cloprostenol intravulvar, in two phases of estrus cycle. In group 1 (T1) were made 79 aplications between $5^{\text {th }}$ and $8^{\text {th }}$ day of estrous cycle, and in group 2 (T2) 128 aplications between $9^{\text {th }}$ and $17^{\text {th }}$ day. The animals were kept with bulls androgenized cows and was observed the estrus three times a day $(30 \mathrm{~min})$. The efficience of synchronization was $63.4 \%$ for $\mathrm{T} 1$ and $80.2 \%$ for $\mathrm{T} 2(\mathrm{p}<0,05)$. The interval aplication-estrus was $57.44+10.13 \mathrm{hr}$ for T1 and $71.87+$ $22.02 \mathrm{hr}$ for T2 $(p<0,01)$. We conclude that estrous cycle phase have been influenced by the interval aplication-estrus and efficience of synchronization.

Key words: estrus synchronization; follicle; bovine

\section{Referências bibliográficas}

Adams GP 1994. Control of ovarian follicular wave dynamics in cattle: Implications for synchronization and superestimulation. Theriogenology 41(1): 19-24.

Adams GP, Kot K, Smith CA, Ginter OJ 1993. Selection of dominante follicle and supression of follicular growth in heifers. Anim Reprod Sci 30: 259-271.

Euclides RF 1982. Sistema de Análise Estatística e Genética, Universidade Federal de Viçosa, Central de Processamento de Dados, Viçosa, MG, 68 pp.
Fernandes CAC 1994. Efeito do tratamento com hormônio folículo estimulante (FSH) sobre a taxa de concepção de novilhas mestiças usadas como receptoras de embrião. Tese de Mestrado, Universidade Federal de Viçosa, 63 pp.

Fortune JE 1993. Follicular dynamics during the bovine estrous cycle: A limiting factor in improvement of fertility? Anim Reprod Sci 33: 11-125.

Fortune JE, Sirois J, Quirk SM 1988. The growth and differentiation of ovarian follicles during the bovine estrous cicle. Theriogenology 29: 95-109.

Gonzalez FHD 1991. Efeito da condição corporal de novilhas sobre a fertilidade, o perfil metabólico pós-serviço e a sobrevivência embrionária. Tese de Doutorado, Universidade Federal de Viçosa, $110 \mathrm{pp}$.

Hafez ESSE 1987. Reproduction in Farm Animals, $5^{\text {a }}$ ed., Lea \& Febiger, Philadelphia, $649 \mathrm{pp}$.

Henricks DM, Dickey JF, Niswender GD 1970. Serum luteinizing hormone and plasma progesterone levels during the estrous cycle and early pregnancy in cows. Biol Reprod Champaign 2: 346-351.

Ireland JJ, Roche JF 1983. Development of nonovulatory antral follicles in heifers. Change in steroids in folicular fluids and receptors for gonadotrophins. Endocrinology 2(12): 150-156.

Kastelic JP, Knopf L, Ginther OJ 1990. Effect of day of prostaglandin- $\mathrm{F}_{2 \alpha}$ treatment on selection and development of the ovulatory follicle in heifers. Anim Reprod Sci 23:169180.

Ko JCH, Kastelic JP, Del Campo MR et al. 1991. Mecanisms of dominant follicle on ovarian follicular dynamics during the oestrus cycle in heifers. J Reprod Fert 91: 511-519.

MacMillan KL, Henderson HV 1983. Analyses of the variation in the interval of the injection of prostaglandin $F_{2 \alpha}$ to estrus as a method of studying patterns of follicular development during diestrous in dairy cows. Anim Reprod Sci 6: 245-254.

Matton P, Adelakoun V, Couture Y, Dufour JJ 1981. Growth and replacement of the bovine ovarian follicles during the estrous cycle. J Anim Sci 52: 813-820.

Momont HW, Seguin BE 1992. Influence of day of estrous cycle on response to $\mathrm{PGF}_{2 \text {-alfa }}$ products: Implications for $\mathrm{Al}$ programs for dairy cattle. Anim Reprod Sci 28: 326.

Pierson RA, Ginger OJ 1987a. Follicular population during the estrus cycle in heifers. II. Influence of right and left sides and intraovarian effect of the corpus luteum. Anim Reprod Sci 14: 177-186.

Pierson RA, Ginter OJ 1987b. Follicular population during the estrus cycle in heifers. III. Time of selection of the ovulatory follicle. Anim Reprod Sci 14: 177-186.

Quirk SM, Hickey GJ, Fortune JE 1986. Growth and regression of ovarian follicles during the follicular phase of the oestrous cycle in heifers undergoing spontaneus and PGF-2 $\alpha$-induced luteolysis. J Reprod Fert 77: 211-219.

Rajakoski $E 1960$. The ovarian follicular system in sexually mature heifers with special reference to seazonal cyclical, and left-right variations. Acta Endocrinol 52 Suppl: 1-68.

Sirois J, Fortune JE 1988. Ovarian follicular dynamics during the estrous cycle in heifers monitored by real-time ultrasonography. Biol Reprod 39: 308-317.

Spicer LJ, Echternkamp SE 1986. Ovarian folicular growth, function and turnover in cattle: A review. J Anim Sci 62: 428451. 